\title{
A SISTEMATIZAÇÃO SIMBÓLICA COMO PROPEDÊUTICA DA FUNÇÃO GERAL DAS CIÊNCIAS
}

CAPELA, Rita Josélia da ${ }^{1}$

\section{RESUMO:}

Toda ciência seja ela física, humana ou social tem uma função geral única que se sobrepõe às suas funções específicas: a de ordenar, relacionar fatos equidistantes e aparentemente independentes; buscar um fio condutor frente ao descontínuo; destacar "alvo" do múltiplo sem dilacerá-lo ou contundi-lo. Assim, encaminharemos nosso trabalho na perspectiva de mostrar como isto é possível, e até mesmo tornou-se necessário. No caso da física, veremos que esta consegue seu lugar, realizando esta tarefa geral, num e por um simbolismo matemático.

PalaVRas-Chave: Filosofia - Ciência - Cassirer - Formas Simbólicas - Pitágoras - Matemática.

\begin{abstract}
:
Science, no matter physical, human or social, has a common general function that overlaps specific functions, such as ordering, relating equidistant but apparently independent facts; search for a conducting wire to deal with the discontinuity and highlighting the multiplicity of the target without shredding or destroying it. Thus, we intend to develop our work in the perspective of showing how it is possible and necessary. In Physics, we will notice that it has its place as it performs this general task in and by a mathematical symbolism.
\end{abstract}

KeYwORDS: Philosophy - Science - Cassirer - Symbolic Forms - Pythagoras - Mathematics.

Segundo o pensamento de Cassirer, a "ciência", em seu sentido específico, teve início com Pitágoras, estando soterrada por toda a idade antiga e média, sendo retomada com o renascimento na figura de Descartes. Considera a ciência como o pináculo e a consumação de todas as atividades humanas, o capítulo derradeiro da "história da humanidade" e o tema mais importante de uma "filosofia sobre o homem". A ciência, em seu sentido específico, faz ver em si mesma, como sua função, a doação de sentido próprio e verdadeiro ao mundo, na medida em que o coloca como constante.

Heráclito havia dito que o mundo é um constante devir. Mas Arquimedes tam-

\footnotetext{
${ }^{1}$ Doutora em Filosofia: Filosofia Luso Brasileira pela UGF. Professora Associada da UERJ. E-mail: ritacapela@ig.com.br
} 
bém havia dito: "dai-me um ponto de apoio e moverei o universo". O pensamento científico é capaz de fixar pontos de repouso, polos inamovíveis no universo mutável. "O processo científico conduz a um equilíbrio estável, à estabilização e à consolidação do mundo das nossas percepções e pensamentos" (CASSIRER, 1972, p. 326).

Tal ideia foi abordada, pela primeira vez, por Cassirer no livro Substance and Function. Nesta obra, reconhece como preocupação fundamental o esboço de uma "Filosofia da Ciência" que, como tal, encontra como "inconcussum" a noção de conceito. Não o conceito entendido nos moldes do pensamento aristotélico - processo de abstração que capta a coisa em si, ou o conceito entendido como representação psicológica; mas sim o conceito articulado como ordenação serial, o qual busca relacionar "nossas percepções" por uma regra préestabelecida. Trata-se de entender o conceito como um caso especial de função que possibilitará, em última instância, a abordagem do singular no escopo da universalidade.

Além de conduzir a um equilíbrio estável de nossas percepções, o processo científico é capaz de apresentar a unidade sintética do múltiplo da intuição, através dos conceitos científicos; conceitos estes que são conceitos do entendimento puro, capazes de dar aos fenômenos sua unidade sintética. Vemos, claramente assumida, a posição kantiana, pois, o que Kant faz em realidade é colocar a questão da objetividade do conhecimento indissoluvelmente ligada ao fato da ciência.

Segundo Kant (1985), a experiência é, sem dúvida, o primeiro produto de nosso entendimento, mas não é um fato simples. Todo fenômeno é um composto de dois fatores opostos: matéria e forma. $O$ fator material é apreendido pelas formas a priori da sensibilidade: espaço e tempo; o formal, representado pelos nossos conceitos científicos a partir das categorias a priori do entendimento.

Vemos, então, que a ciência tem, por fundamento de sua objetividade, um sujeito que é sujeito próprio para o conhecimento; um sujeito portador de condições a priori de conhecimento, 0 sujeito transcendental ${ }^{2}$ portador de objetividade.

A isto Kant (1985) chamava de condições a priori de possibilidades para o conhecimento e objetividade do conhecimento. Cassirer (1953), juntamente com outros filósofos da natureza e físicos, chamará de estrutura matemática ou instrumental lógico de abordagem do real. A "ciência" começa com uma busca de simplicidade lógica, simplicidade esta que não percebemos nos conceitos científicos de épocas aquém; são conceitos místicos. Hoje temos a química, mas para isto tivemos a alquimia; a astronomia, depois da astrologia.

No progresso da ciência verificamos como medida nova, um diferente padrão lógico de verdade. Uma verdade não atingível, enquanto o homem confinou-se no círculo estreito de sua experiência, imediata de fatos observáveis. O progresso marcante verificado na ciência é sua necessidade em dar-nos uma visão compreensiva dos fenômenos, negando-se a descrever fatos destacados e isolados.

O discurso científico é um discurso que procura estabelecer uma relação entre fatos observados; não uma relação de similaridade, mas uma relação de ordenação.

\footnotetext{
2 Ao tratar sobre a questão de como é possível o conhecimento, Kant afirma o papel de sujeito transcendental na constituição do mundo, isto é, é o sujeito quem possui as condições de possibilidades da experiência. O que equivale a dizer que o conhecimento é possível porque o homem possui faculdades que o tornam possível (KANT, 1985, p. 150).
} 
A visão compreensiva que a ciência alcança não pode ser alcançada por uma simples extensão e um enriquecimento da experiência comum. Exige-se um novo princípio de ordenação - além da intuição imediata dos fenômenos observáveis. É a linguagem, a primeira tentativa do homem para articular o mundo de suas percepções, pois é ela o meio que torna manifesto o instinto classificador existente em seu ser.

Entretanto, as primeiras classificações que encontramos na linguagem humana não têm uma finalidade rigorosamente teórica, mas teórico-prática. Enuncia-se os objetos como pertencentes a alguma classe por suas similaridades e por uma questão teleológica - a possibilidade de referirmo-nos a objetos distintos com um mesmo nome como, por exemplo, falar de baleia como um peixe, da borboleta como ave ou da criança como homem.

Nestes termos, a primeira preocupação da ciência foi a de cunhar termos classificatórios. É a criação desta terminologia sistemática que permite à ciência uma ordenação do mundo, que possibilita um mundo constante.

Daí Cassirer (1953) dizer que os conceitos científicos operam como instrumentos de abordagem do real; sistemas de ordenação serial operacionalizados pelo homem quando da necessidade de compreender 0 mundo a partir de suas manifestações fenomênicas e em seus mais diferentes níveis; quer se trate de um nível físico, biológico ou químico. Todo sistema é uma obra de arte, resultado de uma atividade criadora consciente. A teoria de Darwin, por exemplo, apoia-se numa teoria geral da evolução, evolução esta, que não é um mero relato da história natural, mas uma hipótese científica; uma máxima reguladora para nossa observação e classificação dos fenômenos naturais. A evolução, enquanto tal, é fator natural, mas a "teoria da evolução", enquanto relacionando aspectos, levantando questões, afirmando ordenação, é artificial; criação de toda uma elaboração conceitual pré-estabelecida por uma regra que fundamenta a relação, a ordenação expressa pela teoria.

Assim, nossa preocupação, até o presente momento, concentrou-se em mostrar que a ciência, entendida como processo de ordenação do real, quer dizer, enquanto capacidade de falar do caótico, do disperso, de fixar pontos de repouso no imóvel, origina-se do mesmo instinto classificador existente no homem que o leva a construir uma linguagem.

Há um "fio de continuidade", como diz Cassirer, entre a linguagem e a ciência. Trata-se apenas de perceber que, o que é feito inconscientemente na linguagem é conscientemente pretendido e metodicamente executado no processo científico. "A criação de urna terminologia sistemática coerente não é, de maneira alguma, simples característica acessória da ciência; é um de seus elementos inerentes e indispensáveis" (CASSIRER, 1972, p. 329).

Aristóteles, por exemplo, mantém a ciência muito presa à linguagem ordinária; os nomes comuns têm ainda grande influência sobre o pensamento científico, o que se justifica pelo fato de sua noção de "conceito" manter uma íntima relação com a sua concepção metafísica de "ser". A lógica Aristotélica - fundamento de sua ciência - é, em questão, uma decorrência de seu modo de ver e entender o mundo.

Somente com Pitágoras a Filosofia Grega descobre uma nova linguagem, uma linguagem apurada para abordar o real; a linguagem dos números. É este momento que assinala "a hora natalícia de nossa moderna concepção de ciência" (CASSIRER, 1972, p. 330). 
Os pitagóricos foram os primeiros a conceber o número como elemento que a tudo abrange, sendo realmente universal. "E o certo é que todas as coisas que se conhece têm número, pois sem ele nada se pode pensar ou conhecer" (RIBEIRO JR., 2013, p 33. A verdade do mundo se encontra nos números; é neles e por eles que encontramos um universo inteligível.

Conta a história que Pitágoras se voltou para a questão do número quando descobriu que a altura do som dependia do comprimento das cordas que vibravam. Não foi o fato em si, mas sua interpretação que se tornou decisiva para a futura orientação do pensamento filosófico e matemático.

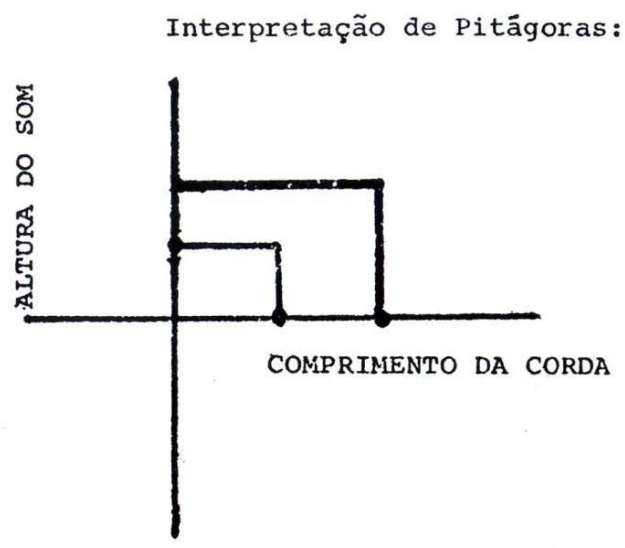

Fig. 1 - Interpretação de Pitagóras.

Neste momento, o mistério da ilustração acima se desvela: a beleza é a verdade matemática. Se essa verdade (beleza) expressa na harmonia dos sons pode ser descrita em uma relação numérica, é o número que nos revela a estrutura fundamental da ordem cósmica.

O problema que Cassirer (1953) levanta é que Pitágoras não percebeu ser este mundo do número um mundo simbólico, e que era este mundo, o mundo do seu dis- curso. Não havia uma distinção entre símbolo e objeto. O símbolo não só explicava o objeto como, sem dúvida, tomava-Ihe o lugar. O ser pitagórico é o número.

Esta tese Pitagórica já não mais se sustenta. O número já não tem uma realidade substancial, embora o possamos reconhecer como uma função fundamental do conhecimento humano, um passo necessário no processo de objetivação.

Este processo de objetivação inicia-se na linguagem - conforme já vimos, na necessidade do homem de classificar as coisas existentes no mundo - mas na ciência assume uma forma nova. O simbolismo que a linguagem utiliza não é o "simbolismo do número" - que é de uma forma lógica diversa. Os símbolos da linguagem não têm ordem sistemática definida. Quando dizemos mesa, por exemplo, referimo-nos a uma série de objetos que denominamos de "mesa", independentes do contexto no qual aparecem. Os símbolos da linguagem referem-se sempre a objetos concretos, isolados; ao passo que, no caso dos números, torna-se claro que a sua essência não é algo de absoluto, mas de relativo. O número, enquanto tal, não é uma realidade substancial, mas relacional; não é um ser, mas um valor. Um número é apenas um lugar singular numa ordem sistemática geral. Seu significado, que é um valor, é definido pela posição que ocupa no conjunto do sistema numérico; somente faz sentido num e por um contexto.

Nas teorias de Frege, Russell, Piano e Dedeking o número não tem mistério ontológico. Seu simbolismo é superior ao simbolismo da linguagem, os números não são palavras isoladas, nem representam coisas isoladas, são termos de uma relação.

Os Pitagóricos encontram no número uma perfeita harmonia de todas as espécies de seres e de todas as formas de conheci- 
mento, percepção, intuição e pensamento.

O descobrimento das distâncias incomensuráveis se colocou como um impasse para esta tese ao longo da história da ciência, levando a uma desarmonia entre a aritmética e a geometria; entre o mundo dos números racionais e o mundo das quantidades contínuas. Tal impasse se desfez com a descoberta matemática dos números irracionais, das frações, etc., que acarreta, em termos de situação das ciências físicas, a abordagem do real em termos quantitativos, através da reintrodução de um instrumental matemático, quando da sua abordagem.

Com a introdução destas novas classes de números, não se criam novos objetos, porém novos símbolos. Amplia-se uma linguagem, um instrumental. Tais quais os números naturais, os números irracionais e fracionários não se colocam como descrições, nem imagens de coisas concretas, objetos físicos, mas como expressão de relações; relações mais complexas do que as expressões pelos números naturais. Os novos números não são símbolos de simples relações, porém de "Relações de Relações", "De Relações de Relações de relações".

Segundo Cassirer (1953), é importante observar que este desenvolvimento, esta ampliação da classe numérica, para além dos números naturais, deve à Filosofia da Matemática a sua fundamentação epistemológica. Uma filosofia deste tipo teve como tarefa provar que a mudança ocorrida não se tratava de uma mudança da natureza e essência do número, mas de uma mudança de sentido que elucidava, cada vez mais, o caráter eficaz dos números inteiros, enquanto capazes de fundamentar uma relação entre quantidades comensuráveis, ao mesmo tempo em que preenchia a lacuna entre esses números e o mundo dos acontecimentos físicos contidos no "Continuum" do espaço e do tempo, através do desenvolvi- mento do vocabulário, da morfologia e da sintaxe desta linguagem simbólica expressa pelos números naturais. Em síntese, a "Filosofia da Matemática" fundamenta a introdução de novos símbolos matemáticos, capazes de expressar relações entre objetos físicos no espaço/tempo.

Descartes, com a sua geometria analítica, formula a primeira prova convincente da relação extensão-número, colocando a geometria como parte de uma Mathesis Universalis. A partir de então, em todos os seus ramos isolados, a física tende para o mesmo ponto: tentativa de trazer o mundo dos fenômenos naturais para o controle dos números.

Esta tentativa emergente, com toda força na física pós-cartesiana, constituiu-se num ideal metodológico, permitindo a Cassirer (1972, p. 331) afirmar que "neste metodológico não encontramos antagonismo entre a física clássica e a física moderna, uma vez que a 'mecânica quântica', em certo sentido, é o verdadeiro renascimento, a renovação e a confirmação do ideal pitagórico clássico".

$\mathrm{Na}$ própria filosofia da natureza, disciplina relativamente recente, vemos presente a necessidade de converter a filosofia numa reflexão crítica, rigorosa sobre a ciência, matéria capaz de ressaltar o homem na abordagem universal de questões e fenômenos singulares, através de estudos sobre "o espírito científico". O que parece ser o propósito de Cassirer ao abordar a teoria científica como uma filosofia do conceito.

As ciências ditas formais abstraem as "coisas" reais, substituindo-as por símbolos, que são apenas índices dessas "coisas". Representam o singular, não no sentido de uma descrição, mas no sentido de um "papel". As "coisas" não são coisas, mas termos de uma relação. O que realmente importa é a relação, e, como toda relação Inclui ter- 
mos, é necessário representar esses termos de uma ou outra maneira. Isso explica o papel das variáveis - que é puramente funcional - para a abordagem do real.

Enquanto Aristóteles dizia que não há ciência do "singular", atualmente desenvolvemos ciência do singular. Singular e particular não são termos sinônimos. De tal forma que fazemos ciência do singular sob uma modalidade de generalidade. Trata-se de um singular generalizado e não particular. Uma generalização formal que, segundo Cassirer (1953), se expressa no conceito de número.

Segundo Jean Ladrière (1978), por exemplo, a ciência de hoje não busca apenas descrever um fato, mas fundamentar a sua própria existência no momento da descrição. Ela não é apenas um conhecimento do conteúdo do domínio estudado, mas se torna um conhecimento das operações por meio das quais esse domínio pode ser construído; introduz uma "subjetividade" operante, o cientista se torna cônscio da maneira pela qual ele conhece. Há em toda ciência um discernimento da "essência" mesma de seu domínio próprio; não no sentido de uma pura e simples intuição, mas no sentido de uma caracterização global de um campo operativo. A ciência conhece o mundo em seu efetuar-se, conhece o resultado da gênese; "reestrutura o já estruturado".

Citou-se o pensamento de Ladrière, no contexto, justamente para fundamentar a posição de Cassirer. De certa forma, podemos dizer que Ladrière (1978) o retoma quando afirma que a ciência "reestrutura o já estruturado". Ora, se Cassirer (1953) admite que toda teoria científica é uma filosofia do conceito de número, colocando este conceito como um caso especial de função, ou seja, algo capaz de estabelecer um "elo" entre os fenômenos observados por uma regra pré-estabelecida que origina e orienta a própria intuição - experiência sensível, devemos supor que espera da ciência uma reestruturação do real a partir desta observação orientada dos fenômenos que nele ocorrem.

Ainda na linha de uma filosofia da natureza encerrada na preocupação de elucidar o espírito científico, pode-se citar a curiosa figura de Gaston Bachelard. Trata-se de um caso curioso na "História da Ciência", porque faz filosofia da ciência, tendo como formação básica a matemática. Esforça-se por justificar e caracterizar o espírito científico na ciência contemporânea.

Na obra La Formation de L'esprit Scientifique, Bachelard (1938) aborda três etapas na história da ciência que constituem as fases de desenvolvimento do espírito científico:

- Antiguidade clássica - Estado précientífico - até o século XVIII.

- Estado Científico em Preparação século XVIII, início século XIX.

- "Novo espírito científico" - a partir de 1905 , no momento em que a relatividade einsteiniana vem dar uma nova expressão ao "espírito científico".

De certa forma, pode-se dizer que há uma precipitação em Bachelard ao fazer esta divisão, e uma contradição. Uma precipitação porque deve parecer-nos um erro colocar Galileu, Kepler e Newton num estado pré-científico. Uma contradição porque coloca a humanidade desde o início num Estado pré-científico. Depois, de repente, marca o ano de 1905 para o início do "novo espírito científico".

Bem, por ora deixemos estas questões de lado, para aprofundarmos o que seja este "novo espírito científico" em Bachelard, uma vez que nossa intenção, ao citá-lo, foi tentar estabelecer uma ponte entre o seu pensamento científico e o pensamento de 
Cassirer.

Antes de abordar esta questão, pensase que seja de extrema importância deixar claro que não se trata de assegurar que as tomadas de posições, métodos e modos de conceber a ciência é que se identificam nos pensamentos de Bachelard e Cassirer, mas sim o modo último de conceber a tarefa científica - como um modo objetivo de abordagem da multiplicidade do real, numa unidade pré-estabelecida a toda e qualquer intuição de expressões fenomênicas.

Não convém, de modo algum, falar numa semelhança ou analogia, em termos de concepção de ciência, no sentido amplo da questão - mesmo porque Bachelard acreditava nos "cortes epistemológicos"; o que não parece ser o caso de Cassirer quando se propõe a fazer uma filosofia do conceito para fundamentar a ciência atual operando com o simbolismo dos números, com a linguagem Pitagórica. Cassirer (1953) é capaz de reconhecer que nada é gratuito: a matemática babilônica favoreceu a Arquimedes, que se refletiu na matemática moderna - na geometria analítica de Descartes - e assim sucessivamente.

Após este breve parêntese, vejamos a posição de Bachelard (1938): a ciência moderna se funda no projeto. Com relação à objetividade científica, eis aí um problema, sobre o qual cabe toda uma discussão. Os dados em si são objetivos, mas a conexão destes dados seria um problema subjetivo, arbitrário, desde que não aprendemos uma conexão, um projeto, existente na realidade? A objetividade consistirá simplesmente em colher dados na realidade? Está em realizar uma experiência e colher um dado; ou é preciso colher a forma pela qual este dado isolado se vincula com outros?

Deve-se responder a essas questões dizendo que, ao lado do postulado, a ciência moderna se funda num projeto, encontra- mos outro que afirma a sua objetividade na verificação. A verificação é que vai revelar o problema do projeto que existe no conhecimento científico. Em ciência, não há verificação, experiência, sem uma elaboração teórica prévia. No cotidiano, olhamos um livro; temos uma verificação imediata: olhou e viu, conheceu.

$\mathrm{Na}$ abordagem científica, não ocorre esta verificação imediata. Ela é complexa e mediata. É mediante um sistema elaborado de leis que constatamos algo. A ciência moderna se funda num projeto. Há um esquema teórico matemático proposto, antes que se parta para uma verificação. Este projeto, teoria, ou ainda, este sistema matemático elaborado é o processo, o método adequado para realizar um conhecimento próprio e torná-lo objetivo, universal.

A verificação científica não se reduz ao simples reconhecimento ou colheita de um objeto já conhecido, mas ao conhecimento, à colheita de algo novo; ao conhecimento da forma como objetos dispostos no espaço e tempo podem se relacionar. A ciência está num plano de conhecimento elaborado. Não há conhecimento científico sem um "projeto". "Projeto" no sentido de se ter consciência de que buscamos fundamentar uma relação no todo. Não é um projeto do que vou encontrar, mas do que posso encontrar.

Há um "vetor epistemológico"; o conhecimento tem uma direção, do racional para o real. A meditação do objeto pelo sujeito toma sempre a forma de um "projeto". Não se trata de apreender um dado, tal qual ele se apresenta no real, mas de uma estrutura de abordagem. Trata-se de uma colheita, onde a razão estabelece uma diretriz na apreensão deste dado. Não aprendemos um dado para depois refletir sobre ele. Há toda uma elaboração racional antecedendo a própria percepção.

No entender de Bachelard (1946), a 
ciência não se contenta com o "como" descritivo; ela procura o "porquê" matemático. O projeto que fazemos sobre a experiência é estruturado em termos matemáticos. 0 instrumental matemático é a estrutura do projeto; daí dizermos que o racionalismo de Bachelard é um racionalismo aplicado, tendo em vista a realização de uma experiência sobre controle; busca a síntese entre o projeto - a estrutura racional que antecede a experiência - e a própria experiência. temático?

Em que consiste então o "porquê" ma-

Consiste na exigência de sistematização, para além de uma mera descrição prática. O problema, aqui, consiste em perceber e fundamentar a necessidade de uma estrutura matemática funcionando na experiência como um sistema axiomático; um sistema que fala sobre o real, traduzindo as expressões fenomênicas em relações matemáticas. A ciência atual conhece o real por um sistema de axiomas de natureza matemática.
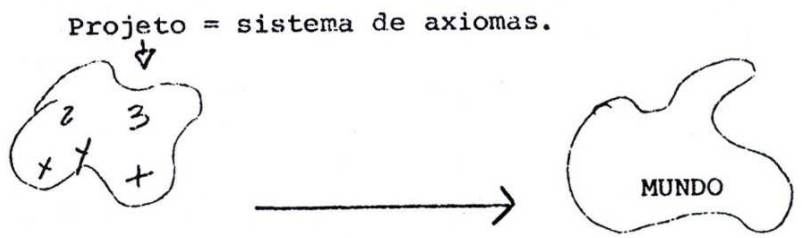

Fig. $2-$ Projeto $=$ sistema de axiomas

Um sistema de axiomas representa a estrutura formal pela qual conhecemos 0 real. São sinais matemáticos que podem ser números ou letras representando grandezas, mais os sinais operativos.

Daí, André Lalande (1948) colocar a ciência como uma razão operando com normas, mostrando que a ciência objetiva um conhecimento capaz de refletir sobre o grau de inteligibilidade do real, baseado num quadro lógico-matemático.

Contudo, segundo Cassirer (1953), foi difícil, até mesmo para a própria matemática, se tornar consciente da nova dimensão que se abria frente ao seu simbolismo. É Leibniz, no século XVII, o primeiro grande pensador moderno a ter uma visão clara do verdadeiro caráter do simbolismo matemático. Há muito se tinha empregado a matemática... mesmo antes que se pudesse explicar o seu caráter lógico específico. $\mathrm{Na}$ filosofia de Platão, por exemplo, o número já não está envolto em mistério; ele se expressa na fé metafísica. No fim de sua vida, Platão assume a posição de um verdadeiro pitagórico; considera o número como a chave de toda verdade e de toda inteligibilidade. Ao expor a sua teoria do mundo ideal, tenta reescrevê-la em termos de número puro. Vê a matemática como o reino intermediário entre o mundo sensível e o inteligível. Reconhece que o poder do número se estende sobre todo o mundo sensível, embora afirme que a essência metafísica do mesmo não pode ser revelada por nenhum fenômeno sensível. Os fenômenos participam desta essência, mas não podem expressá-la adequadamente - ficam necessariamente aquém dela. Os números visíveis que encontramos nos fenômenos naturais, nos movimentos dos corpos, são indicações dos números ideais puros - os quais devem ser apreendidos pela razão e não pela visão.

A matemática moderna já não se considera mais um estudo de coisas, quer visíveis ou invisíveis, mas como um estudo de relações e tipos de relações.

A objetividade do número reside no fato de se colocar como um instrumento para a descoberta e abordagem do real e da natureza.

Como testemunho oculto dessa asserção, Cassirer (1953) nos diz que o pensamento matemático parece amiúde adiantar- 
se à investigação física e cita o caso específico de Einstein que, para desenvolver a sua "teoria da relatividade", voltou à geometria de Riemann - que a havia criado, mas não operacionalizado por considerá-la apenas enquanto possibilidade lógica. Einstein, porém, estava convencido de que precisávamos de tais possibilidades, a fim de estarmos preparados para a descrição dos fatos reais; precisávamos de uma plena liberdade na construção das várias formas de obter 0 pensamento físico com todos os seus instrumentos intelectuais.

Cassirer (1953) acredita que não podemos antecipar os fatos, mas podemos fazer previsões para sua interpretação intelectual, através do poder do pensamento simbólico. Neste momento, a ciência atinge seu objetivo: o de ser determinista. Opera com um determinismo metodológico, o do número - verdadeiro determinismo científi$\underline{\text { co. } O}$ número já não é mais a essência metafísica das coisas (Pitágoras, Platão), mas instrumento específico do conhecimento. $O$ cientista procede, baseado no princípio de que, até nos casos mais complicados, conseguirá finalmente encontrar um simbolismo adequado que the permitirá descrever suas observações numa linguagem universal e universalmente compreensível.

A ciência atual não prescinde dos fatos, apenas os subjulga à linguagem simbólica dos números. Linguagem capaz de fixar no universo mutável pontos de repouso; capaz de abordar o singular de forma universal; capaz de elevar o homem ao seu lugar próprio, de "senhor" do mundo que habita... "Dai-me um ponto de apoio e eu moverei o universo" (CASSIRER, 1953, p. 36).

De um modo bastante geral as propostas de Bachelard, Ladrière, Cassirer, Lalande e muitos outros filósofos da ciência contemporânea encontram-se no fim último de mostrar a impossibilidade de abordarmos a realidade de uma maneira única e privilegiada. $\mathrm{O}$ que pode haver de realmente preciso no conhecimento científico é a consciência de um "Estado Científico". Consciência esta que é feita com bases na relação, sistema de axiomatização para abordagem de um fenômeno determinado $\leftrightarrow$ conhecimento deste fenômeno no sistema. Não temos mais a ideia de uma ordem, um cosmos de leis imutáveis, apenas a ideia de possibilidades deste relacionamento entre conhecimento: aquele que se propõe a conhecer, conhece através do instrumental matemático.

Nesse sentido, a ciência atual sofre uma delimitação, mas a consciência desta delimitação é que lhe dá a sua precisão. $E$, em função desta precisão, se guarda num plano de conhecimento que é instrumento de manipulação do real.

A marca de realidade do mundo físico é a complexidade, a diferenciação. Por isto, a matemática aparece como instrumento capaz de impor a essa massa caótica uma ordem; um conhecimento espiritual que ordena o real, impõe uma relação entre fenômenos particulares e isolados.

O problema de objetividade nas ciências modernas se põe numa posição quantitativa da realidade. Ligada a este problema quantitativo, está a afirmação da substituição de uma realidade constituída de seres, por simples apreensões de relações, fazendo abstração do que se relaciona.

A validade do conhecimento sensível é relativa à sua natureza. Por isso, a validade desse conhecimento ser a de que eu tenho uma impressão - isso é verdadeiro - mas não de que existe o que eu vejo.

A ciência moderna, amparada pelo desenvolvimento da matemática, vai buscar uma ciência experimental a partir do conhecimento intelectual. Vai explicar e aplicar 
uma "experiência espiritualista" da ciência, através da matematização que representa um plano de pensamento aspirante da não intervenção de qualquer elemento sensível. Aspira-se a um conhecimento do real que seja puramente intelectual, inspirado no matemático.

Em lugar de nos determos nas variações particulares que a natureza apresenta e, por conseguinte, na instabilidade, tentaremos ultrapassar esta variabilidade e chegar a um conhecimento de alcance da realidade. Para isto, a ciência apresenta como solução implantar uma posição critica, questionando o conhecimento sensível e valorizando o racional.

É um depuramento do sensível, em prol do racional, pois não existe conhecimento sensível que não seja acompanhado de atitude Intelectual. O problema não está em rejeitar a objetividade do dado sensível, mas sim em ter consciência de que ele é relacionado e articulado por uma "intuição intelectual" que se fundamenta na matemática. Quando se sustenta que a ciência moderna é ordenada matematicamente, sustenta-se, também, que é ordenada segundo uma estrutura puramente intelectual. A razão será a própria relação causal, é ela que estrutura teórica e racionalmente o real.

É aqui que Cassirer (1953) entra com a sua filosofia do conceito, mostrando que o conceito de número é uma relação que ordena, pois permite apreender os fenômenos físicos por uma relação. E neste sentido é que entendo e vejo a possibilidade do singular tomado no escopo da universalidade. Porque se os números são grandes valores que falam do real, e os arrumamos numa série, numa linguagem simbólica universalmente aceita, certamente que a coisa representada por aquele valor, sem perder a sua condição de singular, será também percebida universalmente.
Enfim, os conceitos científicos atuais não têm por base uma metafísica Aristotélica; mas Pitagórica. A ciência atual não fala a linguagem cotidiana da experiência sensorial, mas a linguagem simbólica dos números. O simbolismo do número supera e suprime o simbolismo da linguagem.

Dessa forma, o poeta Novalis (apud PLUM, 1967, p. 51) admoesta-nos:

Toda ciência histórica tende a tornar-se matemática. A virtude da matemática é o poder organizar. Toda ciência matemática tende novamente a tornar-se filosófica; depois poética, enfim moral e, em seu acabamento, religiosa. Finalmente, toda matemática de forma alguma constitui uma ciência particular, mas somente um instrumento geral do conjunto das ciências. Talvez ela não seja senão a exteriorização da força espiritual da inteligência, essa força transformada em objeto e em órgão externo: uma inteligência realizada e objetivada. Não deveria ocorrer o mesmo com todas as forças espirituais? Tudo deve sair de nós e tornar-se visível. O sistema das ciências deve tornar-se o corpo simbólico (o sistema dos órgãos) de nosso espírito. Nosso espírito deve tornar-se máquina perceptível pelos sentidos, não no interior, mas fora de nós.

No conceito de números, que é um conceito científico, não copiamos mais as coisas isoladas em sua singularidade; copiar significa rearrumar as coisas num sistema de ordenação serial, pré-estabelecido por uma regra de relação, "the copying does not producing a new thing, but a new necessary order among operation of thought and objects of thought" (CASSIRER, 1953, p. 36).

Podemos, assim, dizer que o "conceito de número" deu à ciência contemporânea o "ponto de partida" que Arquimedes tanto procurou para construir o seu universo. 


\section{REFERÊNCIAS BIBLIOGRÁFICAS:}

BACHELARD, F. Le Nouvel Esprit Scientifique. Paris: Puf, 1946.

\section{La Formation de L'esprit}

Scientifique. Paris: Vrin, 1938.

CASSIRER, E. Antropologia Filosófica. Trad. Vicente Félix de Queiroz. São Paulo: Mestre Jou, 1972.

\section{Substance and Function \&}

Einstein's Theory of Relativity. Chicago: Dover publication, 1953.

DAUMAS, Maurice. Historie de Ia Science. Encyclopédie de Ia Pléiade. Gallimard: Bruges, 1963.

KANT, Immanuel. Crítica da Razão Pura. Trad. Manuela P. dos Santos e Alexandre F. Morujão. Lisboa: Caluste Gulbenkian, 1985.

LADRIÈRE, J. Filosofia e Práxis Científica. Francisco Alves, 1978.

LALANDE, André. La Raison et les normes. Essai sur le Principe et sur la Logique des Jugements de Valeur. Paris, 1948.

PLUM, Werner. Les Sciences de La Nature et La Technique sur La Voie de La Révolution Industrielle. Bonn, 1967.

RIBEIRO JR., W. A. Filolau de Crotona: fragmentos. Portal Graecia Antiqua. São Carlos. Disponível em: www.greciantiga.org/arquivo.asp?num $=016$ 7. Acesso em: 31 de maio de 2013. 